\title{
Content and Language Integrated Learning: Creating Awareness through Language Teaching
}

\author{
Helen Osieja* \\ Teaching and Learning Adviser, Stockholm, Sweden
}

*Corresponding author: hosieja@yahoo.se

Received April 02, 2015; Revised May 20, 2015; Accepted June 03, 2015

\begin{abstract}
The challenges that humanity faces in the $21^{\text {st }}$ century are overwhelming, to the point that the very survival of humanity and the ecosystem are jeopardized. Yet, most people in the West are "comfortably unaware" of the consequences of their lifestyles for the planet Earth as an ecosystem as well as for its inhabitants, human and animal. Language teachers can become agents of change by choosing environmental, human and animal rights topics as reading material and as themes for group discussion starting from a B1 language level. The acquisitive nature of education in the 21st century has neglected the human side of education- that is, of developing the individual's personality, empathy and awareness. The aim of this paper is to create awareness of the problems humanity faces in the 21st century by including transcendental values in our language courses. Using our academic freedom responsibly, we will not only improve our students' language skills, but develop their critical and analytical skills and seek solutions to global problems.
\end{abstract}

Keywords: language teaching, awareness, integrated learning, human development

Cite This Article: Helen Osieja, "XContent and Language Integrated Learning: Creating Awareness through Language Teaching." American Journal of Educational Research, vol. 3, no. 6 (2015): 790-792. doi: 10.12691/education-3-6-19.

\section{The Cleavage between Knowledge Acquisition and Human Development}

Education has increasingly become a purchasable good instead of an ongoing process of human development. In the corporate capitalist system of the $21^{\text {st }}$ century, higher as well as vocational school curricula are limited to providing students with marketable skills which enable them to enter an ever more demanding labour market. Education has thus become acquisitive, that is, limited to acquiring degrees which satisfy the demands of employers. The human dimension of the students has become thus neglected as a result of need businesses to maintain "competitive edge" and increase efficiency. Furthermore, the fact that in most Western households both parents work, children have a need of other role models to provide them with values. Therefore, the responsibility of the teacher has become much more than a transmitter of knowledge and facts. Teachers have become role models in societies where broken homes have become more the rule than the exception.

According to the 2004 United Nations world report, juvenile delinquency has become a worldwide problem. In the wealthy industrialized countries, increasing rates of both property and violent crime have occurred- even in countries in which the crime rate among adults has remained stable or increased only moderately. Likewise, suicide has become one of the main causes of death in industrialized countries. Although the benchmarking criteria of international education like the PISA evaluation are effective tools for measuring academic achievement, they provide no information about the mental health and well-being of the students. In Sweden, adolescent prostitution has become a great concern. The (mostly) girls who engage in prostitution are typically well-off middle- and high school students whose parents have university degrees and good incomes.

In South Korea, whose academic achievement is outstanding, students who do not meet parents' expectations in school are often severely punished. According to the Centre on International Education Benchmarking, $75 \%$ of all middle and high school students consider running away from home or committing suicide because of the pressure they experience at school. Furthermore, some of the most horrific practices of animal cruelty still persist: Every year, around 2.5 million dogs are killed for their meat in South Korea, which is considered a delicacy. Dogs live in tiny raised up cages all their lives. They don't know what it feels like to walk on the ground. Puppies are separated from their mothers at an early age and some are slaughtered at a very young age. They suffer from the summer heat and freezing winters outdoors. Often, they are not even given water. According to some animal rights organizations, they have been known to have their eardrums burst to prevent them from barking. When the time for slaughter comes, dogs are electrocuted, hanged, beaten or burned to death. There is a perverted belief in that "highly educated" country that the higher the adrenaline level of the slaughtered animal, the more flavoursome the meat will be. 
In the United States of America, The Center for Disease Control has classified school violence as a public health problem. According to this institution, there were about 828,000 nonfatal victimizations at schools among students aged 12 to 18 in 2010. [1] The same study points out that less than $2 \%$ of youth homicides take place at school, yet "deaths resulting form school violence are only part of the problem”. Not all consequences of violence are physically visible, though depression, anxiety and other psychological problems caused by school violence can seriously affect the development of young people.

\subsection{Global Problems which Concern All}

According to the World Health Organization report of 2002, around 150 million girls worldwide had been victims of sexual violence. Available data show that anywhere from $36 \%$ to $62 \%$ of reported sexual assaults are committed against girls 15 years or younger. Although this cipher is indeed shocking, it is most likely an underestimate since most cases of sexual violence are not reported to the authorities due to fear or social stigma. The consequences of this type of violence are very profound. According to the 2009 UNICEF report Together for Girls: "In many places, schools are unsafe for girls. The threat of sexual violence is not only a reason some families do not send their daughters to school, but it also may affect a victim's chances of receiving an education.” [2] It is well known that the consequences of depriving girls of obtaining an education is tantamount to condemning them to a life a poverty, economic dependency and social exclusion.

Environmental degradation has become a very serious problem in the 21st century, to the degree that it has now become an issue of survival. The exponential population growth of the last decades together with a consumerist lifestyle jeopardizes the survival of the Earth as an ecosystem.

According to the 2006 Food and Agriculture Organization (FAO) report of 2006 entitled Livestock’s Long Shadow, the livestock industry [3] accounts for $18 \%$ of all greenhouse gas emissions. The production of cheap hamburgers and chicken nuggets are very dear in terms of environmental degradation, deforestation, not to mention animal cruelty. Livestock requires a lot of land: $26 \%$ of the Earth's ice-free land is used for livestock, and the main reason for the increasing deforestation of the Amazon is for fodder production.

It is no news that the seas are becoming the trash bins of the world. According to the Clean Water Action report The Problem of Marine Plastic Pollution of 2010: The amount of marine waste is increasing in oceans worldwide. Researchers at the Algalita Marine Research Foundation documented a rise in plastic debris in the Central Pacific Gyre five-fold between 1997 and 2007, where the baseline in 1997 showed plastic pieces outnumbered plankton on the ocean surface 6:1 [4].

\subsection{The Role of the Teacher in Creating Awareness}

As long as problems are seen as somebody else's, as the responsibility of governments or intergovernmental agencies or organizations, there is very little hope for change. Nonetheless, when we acknowledge our responsibility as consumers and citizens of the world, when we are informed about the situation we are, in fact, in a much better position to effect change. Teachers have the privilege of having a captive audience. Therefore, they can use their academic freedom responsibly and constructively by choosing articles and essays for reading and discussions which address global problems.

Questioning students about the consequences of their lifestyles and possible solutions will not only enhance their reasoning and problem-solving skills, it will very likely create awareness. Talking with our groups about topics which concerns them, their families, and their future is a fundamental step in the development of the citizens of tomorrow. Talking to our students about how we can be cause and not only effect, that we, and not only our political leaders, can be agents of change of the society is fundamental.

It is likely that many of students react with resistance and hostility when teachers present unpleasant facts. Admitting that one as a consumer is responsible or coresponsible for the suffering of others can be painful. The older the students, the more grounded their habits, the more difficult it will be to challenge them. Nevertheless a debate about how it is possible to modify our lifestyles, and the consequences of not doing it would definitely create awareness in the students.

It is fundamental for teachers to ask themselves if they want to be the source of change, or if it is probably more comfortable not to talk about controversial topics and just let things continue as they have always been. It is, after all, quite unpleasant to talk about pressing social and environmental problems because we have no other alternative but to address them. Nevertheless, avoiding these problems will not solve them- they will just become more serious and difficult to solve. As teachers we have the great privilege of having a captive audience. Teachers decide how to speak to their audience. Teachers should know the level of maturity of their students and to what degree the group is ready to discuss topics which are relevant but controversial.

\section{Defining the Aims of Education}

Education can limit itself to providing skills necessary for continuing into a higher program or entering the labor market. Nevertheless, if a change of lifestyle is desired, education has to encompass much more than technical instruction. If we want an ethical society, an ethical world, then ethics should not be a topic taught in philosophy class, but the basis of all subjects. The deontological preparedness of teachers, that is, the development of teachers' professional competence, value orientations, knowledge of the norms of pedagogical ethics, is rarely considered in the current educational industry.

For Aristotle, the way to happiness is through the cultivation of virtue. For this classical Greek thinker, virtue can be cultivated through habit. It follows that education at the early stages should have as one of its main goals the creation of healthy habits.

Erik Erikson considers ethical rules to be based on ideals. In his essay The Golden Rule in the Light of New Insight, Erik Erikson makes a clear distinction between moral rules of conduct and ethical rules: For this 
psychoanalyst, moral rules of conduct are based "on a fear of threats to be forestalled." What counts in any case is the threat. In contrast, ethical rules are based on ideals to be striven for with a high degree of rational assent and with a ready consent to a formulated good, a definition of perfection, and some promise of self-realization”. [5]

\section{Including Inquisitive Skills in Acquisitive Language Courses}

The characteristics of inquisitive education are totally different from the ones of acquisitive education: The individual seeks knowledge to grow as a human being, to enhance his understanding of himself, of others and/or of the world. The aim of inquisitive education is not to obtain a certificate, because grades, if there are any, do not play a role. Knowledge is an aim per se, not a means for a different end other than knowledge and personal growth. As the adjective inquisitive shows, the bases of this type of knowledge are curiosity, inquiry. Knowledge becomes a part of us, it modifies our views. The motivation for this type of knowledge is purely intrinsic- that is, it comes from within us, and neither from the needs of the labor market nor from the urge to obtain a marketable certificate.

The problem for language teachers here is how to include transcendental values in their language courses while attaining the aims of the academic curricula. The advantage language teachers have over the teachers of other subjects is that language is both a means and an end at the same time. Complex topics can readily be introduced at the B1 level. According to the Common European Framework of Reference for Languages (CEFR), the $\mathrm{B} 1$ level is an important level as it bridges the gap between simple and complex language usage. The CEFR says that learners at B1 level:

- Can understand the main points of clear standard input on familiar matters regularly encountered in work, school, leisure, etc.

- Can deal with most situations likely to arise whilst travelling in an area where the language is spoken.

- Can produce simple connected text on topics which are familiar or of personal interest.

- Can describe experiences and events, dreams, hopes and ambitions and briefly give reasons and explanations for opinions and plans.

Of course, language teachers can not expect the students to master the vocabulary contained in complex articles nor to be able to defend their arguments fluently and lucidly, but the aim of obtaining sophisticated vocabulary they will encounter in newspapers and magazines for native speakers as well as the aim of creating an awareness of global problems will definitely be attained.

\section{References}

[1] U.S. Center for Disease Control, Understanding School Violence, Fact Sheet 2012.

[2] Together for Girls, We Can End Sexual Violence, Downloaded on January 11, 2014.

[3] United Nations Food and Agriculture Organization, Livestock's Long Shadow, 2006.

[4] Clean Water Action, The Problem of Marine Plastic Pollution, www.cleanwater.org, November 11, 2010.

[5] Erikson, Erik, The Erikson Reader, Edited by Robert Coles, W.W. Norton \& Company, New York, 2000, p.447. 